\title{
Erratum to: Morphological and Functional Alterations of Alveolar Macrophages in a Murine Model of Chronic Inflammatory Lung Disease
}

\author{
Julia Désirée Boehme ${ }^{1,2}$ - Sabine Pietkiewicz ${ }^{3}$ Inna Lavrik ${ }^{3}$ Andreas Jeron ${ }^{1,2}$ • \\ Dunja Bruder ${ }^{1,2}$
}

Published online: 12 October 2015

(C) Springer Science+Business Media New York 2015

\section{Erratum to: Lung \\ DOI 10.1007/s00408-015-9797-4}

Unfortunately, the given name and family name of the first author was incorrectly published in the original publication. The author name is corrected with this erratum.

The online version of the original article can be found under doi:10.1007/s00408-015-9797-4.

Julia Désirée Boehme

julia.boehme@helmholtz-hzi.de

1 Infection Immunology Group, Institute of Medical Microbiology and Hospital Hygiene, Infection Control and Prevention, Otto-von-Guericke University, Leipziger Straße 44, 39120 Magdeburg, Germany

2 Immune Regulation Group, Helmholtz Centre for Infection Research, Inhoffenstraße 7, 38124 Brunswick, Germany

3 Department of Translational Inflammation Research, Institute of Experimental Internal Medicine, Otto-von-Guericke University, Pfälzer Platz, Gebäude 28, 39106 Magdeburg, Germany 